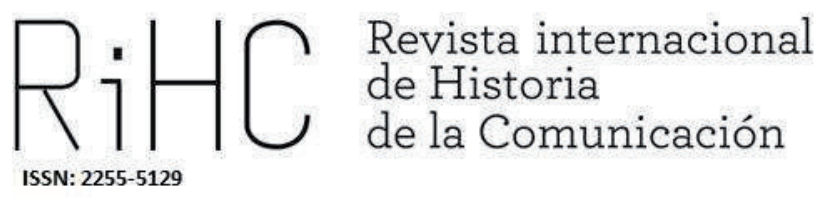

\title{
EL APRENDIZAJE DE LA HISTORIA DE LOS JÓVENES DE LA POSGUERRA: LA REVISTA SALESIANA MI COLEGIO (UTRERA, 1942-1945)
}

The young people and the learning of the History in the postwar period: The salesian magazin Mi Colegio (Utrera, 1942-1945)

DOI: http://dx.doi.org/10.12795/RiCH.2021.i17.04

Recibido: $19-9-2021$

Aceptado: 11-12-2021

María del Carmen Montoya Rodríguez

Universidad de Sevilla

mcmontoya@us.es

ORCID (D) 0000-0002-6448-9429 
Resumen: Este artículo analiza la trayectoria de Mi Colegio, editada en el Colegio salesiano de Utrera, entre 1942 y 1945, años decisivos en la conformación del ideario franquista y de redefinición del papel de España en el orden internacional. Este estudio de caso permite clarificar un modelo de revista salesiana que difiere del jesuítico por sus rasgos periodísticos, sus líneas temáticas preferentes y su finalidad divulgativa. El análisis de contenido permite comprender si la revista responde al modelo educativo salesiano y clarificar la propuesta de persona del centro salesiano en el marco de la posguerra. A partir de un enfoque interpretativo e integrador y atendiendo a los textos publicados accederemos al nuevo modelo de ciudadano que trata de forjarse, con un proyecto de vida acorde con los principios nacionales del Movimiento: patriotismo y catolicidad. Esto nos permitirá señalar los referentes culturales, religiosos e históricos que configuran la propuesta educativa-cívica sobre la que pretende asentarse la reconstrucción nacional.

Palabras clave: prensa escolar, franquismo, propaganda, salesianos, Utrera, historia del periodismo

Abstract: This article analyzes the trajectory of Mi Colegio, published in the Salesian College of Utrera, between 1942 and 1945, decisive years in the conformation of the Franco ideology and redefinition of the role of Spain in the international order. This case study allows to clarify a model of Salesian magazine that differs from the Jesuit by its journalistic features, its preferred thematic lines and its informative purpose. The content analysis allows to understand if the magazine responds to the Salesian educational model and to clarify the proposal of person of the Salesian center in the framework of the postwar period. Based on an interpretative and integrative approach and based on the published texts, we will access the new model of citizen that seeks to be forged, with a life project in accordance with the national principles of the Movement: patriotism and catholicity. This will allow us to point out the cultural, religious and historical references that shape the educational-civic proposal on which the national reconstruction intends to be based.

Keywords: school newspaper, franquismo, propaganda, Salesians, Utrera, journalism's history.

\section{Introducción ${ }^{1}$}

Durante el primer franquismo aparecen en la provincia de Sevilla proyectos periodísticos de índole religiosa, cultural o educativa que animan un panorama anodino y conservador (Langa, 2009), entre ellos algunas revistas escolares. Esta investigación se centra en la revista Mi colegio, del colegio Ntra. Sra del Carmen de Utrera, que inicia su

\footnotetext{
${ }^{1}$ Este trabajo se inscribe en los Proyectos Historia crítica del Periodismo Andaluz, HI[C]PAN, con referencia US 1253132, Programa Operativo FEDER 2014-2020 y Consejería de Economía, Conocimiento, Empresas y Universidad de la Junta de Andalucía e Historia Crítica del Periodismo Andaluz (HICPAN), con referencia P18-RT-1552, Ayudas a la I+D+i del Plan Andaluz de Investigación, desarrollo e innovación (PAIDI 2020) de la Junta de Andalucía (Consejería de Economía y Conocimiento).
} 
andadura en octubre de 1939 y es, por tanto, pionera en la provincia entre las publicaciones escolares de centros confesionales.

En la categoría de prensa escolar se encuadran publicaciones que, total o parcialmente, son realizadas por los alumnos, en los propios centros de enseñanza. Puede considerarse un valioso material de estudio e interpretación de la cultura escolar (Delgado, 2010) y de su propia cultura organizativa (Campos, 1995). El estudio de caso sobre la revista Mi colegio nos permitirá vislumbrar el funcionamiento y los pormenores de la vida cotidiana de las escuelas confesionales durante la posguerra, en este caso, en un colegio salesiano de referencia en el país, por ser el primer centro fundado por la congregación en España.

Waidenfeld (2012) ha puesto de manifiesto cómo el análisis profundo del contenido de las revistas -en su caso de las escuelas católicas de Río de Janeiro en la primera mitad del siglo XX- permite comprender el modelo educativo y la propuesta de persona "arquetipo humano"- que subyace a la práctica educativa, y que va más allá de la relación formativa-escolar. El estudio de los contenidos que ofrece Mi colegio permitirá comprender la propuesta educativa salesiana en el marco de la posguerra. Dos objetivos específicos derivados de esto serán: comprobar si como producto periodístico, $\mathrm{Mi}$ Colegio, responde a esta intuición de Don Bosco y si los objetivos educativos se centran en crear unos referentes para los nuevos ciudadanos, en relación con la reconstrucción de la identidad nacional.

El periodismo educativo va más allá del ámbito escolar. Yanes considera la prensa escolar como un "género dentro del periodismo" (2004: 189-190). Conviene, sin embargo, subrayar que las publicaciones regentadas por órdenes y congregaciones eclesiásticas fueron creadas con una intencionalidad que supera la tradicional finalidad periodística de informar y entretener. Así lo revelan los estudios realizados sobre la revista Auras de Colegio del centro jesuita San José de Valencia (Lull, 1999); la revista ICAl editada por el Instituto Católico de Artes e Industrias de Madrid (García, 2012); sobre la revista Máter de la Compañía de la Pureza de María de Mallorca (Matas, 2012) y sobre la prensa escolar mallorquí publicada durante el franquismo en Mallorca (González, Fullana y Comas, 2014). Por encima de la intencionalidad informativa y cultural, prevalece la voluntad de favorecer la socialización de los alumnos y sus familias, promocionar al centro u obtener fines estrictamente comerciales (Dávila, Naya y Zabaleta, 2017). Son objetivos específicos de esta investigación clarificar la finalidad de la revista Mi Colegio y sus intenciones educativas y culturales, de cara a la comunidad educativa y, finalmente, analizar la función que cumple en relación a su entorno.

Esta investigación asume una perspectiva revisionista y crítica, que permite la ampliación temática y la variedad de fuentes consultadas (Escolano, 1997). Parte de la revisión bibliográfica y teórica procedente de estudios similares, ya que no se han 
realizado estudios previos de esta publicación y el único acercamiento científico a su contexto histórico-educativo (Martín González, 1981) sigue un planteamiento historicista y positivista. Este estudio recurre a una metodología de corte cualitativo, flexible, evolucionaria y recursiva (López Noguero, 2002), centrada en la recolección y análisis de datos que permiten "afinar las preguntas de investigación o revelar nuevas interrogantes en el proceso de interpretación" (Hernández-Sampieri et al., 2014: 7). Superada una primera fase de localización, selección y crítica de fuentes, trasciende al enfoque interpretativo e integrador, siguiendo una línea descriptiva al identificar sus rasgos periodísticos, especificar las características de Mi Colegio y explicativa para el análisis de contenidos.

El corpus de estudio está formado por fuentes primarias hemerográficas, una serie de 22 ejemplares (33 números) de Mi Colegio, entre abril de 1942 y enero de 1945, a excepción del no 1 del año VI (octubre, noviembre, diciembre de 1945) sin localizar. Con el análisis de estos números, que tienen un carácter discursivo, pero también gráfico y numérico, se inicia la fase analítica de la investigación. El marco cronológico de la investigación se acota en el período 1942-1945², unos años clave para asentar los presupuestos del nuevo Estado y el consiguiente modelo educativo del primer franquismo. El objetivo del análisis de documentos no es el estilo del texto, sino las ideas expresadas en él, siendo las temáticas utilizadas y la línea editorial de la revista lo que se clarificará, con especial atención a la línea argumental de los textos publicados sobre la historia de España y su papel histórico. El análisis crítico de los textos periodísticos nos permitirá formular hipótesis generales sobre la enseñanza de la historia que serán validadas o refutadas en sucesivos estudios.

\section{Marco histórico y definición del proyecto de revista}

Mi Colegio arranca en la primera casa salesiana fundada en España, la de Utrera, en 1939, en un contexto general de enormes dificultades, pero también de grandes iniciativas pastorales, como la gran cruzada catequética a la que anima en 1940 el Rector Mayor, Pedro Ricaldone, inspirada en el modelo de oratorio para las clases populares y galardonada por el gobierno italiano con la medalla de oro al mérito escolar ${ }^{3}$. El colegio

\footnotetext{
${ }^{2}$ No hay referencias en los catálogos y fondos locales consultados, tampoco en los digitales (Biblioteca Nacional, Catálogo Colectivo de Patrimonio Bibliográfico español...). Los ejemplares analizados, propiedad de la autora, se digitalizarán y donarán a la Biblioteca Municipal de Utrera y la Hemeroteca Municipal de Sevilla.

${ }^{3}$ Boletín Salesiano, mayo 1940, pp. 99-102. Volverá sobre el tema en julio, agosto y septiembre de 1940, marzo de 1941 y abril de 1943.
} 
Ntra. Sra. del Carmen, que no sufrió consecuencias directas de la guerra y pudo proseguir con su labor en el curso 1937-1938, estaba en una situación bastante favorable institucionalmente. El Inspector de la Bética había conseguido de Queipo de Llano la dispensa para los salesianos de las obligaciones militares por la importante "función docente, social y humanitaria" que debían jugar en la reconstrucción nacional (Martín, 1981: 728). De las buenas relaciones con las autoridades civiles y miliares dan cuentas los actos propagandísticos del primer franquismo que acogieron sus instalaciones ${ }^{4}$.

En 1939, el Colegio de Utrera sobrepasa el millar de alumnos, entre las escuelas gratuitas, los alumnos de primaria y de bachillerato y es el centro salesiano que tiene mayor número de alumnado interno. Fue, además, centro de acogida para el personal en formación de otras inspectorías y ayudó al sostenimiento de las vocaciones y el resurgimiento de las casas salesianas más necesitadas (Martín, 1981: 737).

\subsection{Descripción y equipo humano}

Mi Colegio fue impulsada en 1939 por el director del centro Manuel Fernández Moreno y será "palestra de plumas jóvenes y eco que llevó a todas las latitudes la voz y el nombre del Carmen utrerano" (Martín, 1981: 733). Estuvo liderada entre 1942 y 1948, por dos salesianos, compañeros de claustro y hermanos de comunidad desde 1934 (Martín, 1981: 705): José Holgado, miembro de la comunidad educativa de Utrera desde al menos $1927^{5}$ y profesor de historia y literatura, y Claudio Sánchez, profesor de química.

El estímulo de la cultura y de productos impresos es una seña de identidad de la familia salesiana desde que Don Bosco creara en 1874 Boletín salesiano ${ }^{6}$ aún hoy activo, para mantener informados a los diversos grupos y atender a las necesidades culturales de la sociedad civil. A partir de 1944 tendrá su edición española ${ }^{7}$. Desde 1918 se edita también en España Don Bosco en España ${ }^{8}$, órgano de la Federación de Antiguos Alumnos que

\footnotetext{
${ }^{4}$ En 1938 se celebra en Utrera el primer acto de jura de bandera de las milicias de Falange Española Tradicionalista, del Ejército del Sur. Por la tarde, en el colegio salesiano tuvo lugar otro acto patriótico en el que los niños cantaron el himno del Caudillo ante las autoridades. Azul: órgano de la Falange Española de las J.O.N.S., n.o 660, 18-noviembre-1938, p. 12.

${ }^{5}$ Compuso un saludo poético para la visita de Rinaldi en 1927, así como el recibimiento de Primo de Rivera el 14 de octubre de 1928 (Martín, 1981: 657,660).

6 Bolletino salesiano, Turín, año 3, 5 de agosto de 1877. Disponible en internet (1-junio-2021) https://web.archive.org/web/20080203191420/http://www.sdb.org/BS/BSrete/archivio.aspx

7 La Casa del Boletín Salesiano se funda el 31 de enero de 1944 en Madrid, junto al Centro Catequístico y la Editorial SEI (Sociedad Editora Ibérica), germen de la actual Editorial CCS.

${ }^{8}$ Los dos primeros años (1918-1920) se editó con el título Juventud Salesiana y los dos siguientes años Juventud perenne (1920-1922) y a partir de la III Asamblea Nacional de Antiguos alumnos Salesianos de Barcelona en julio de 1922 adoptaría el nombre que mantiene hasta la actualidad.
} 
desaparece con la República (Álvarez González, 2018: 6). Aunque el colegio utrerano publicaba con asiduidad folletos informativos y toda suerte de impresos ${ }^{9}$, no consta que editase otra publicación periodística anterior a Mi Colegio. Sí que hubo otra publicación escolar en Utrera desde febrero de 1935: Bachillerías, del Instituto público de Bachillerato Rodrigo Caro. Redactada semanalmente por los alumnos, recogía anécdotas de la vida académica y se convirtió en un importante foco de difusión cultural republicana (Sánchez y Mena, 1999).

A diferencia de las publicaciones jesuitas (Mol y Sureda, 2021), con un entramado comunicativo y propagandístico bien definido, no se conoce otra publicación de semejantes características para la Inspectoría de Sevilla. Mi Colegio más que altavoz de la vida académica del centro es una revista cultural que divulga los trabajos literarios y difunde los testimonios de los miembros de su comunidad: alumnos, profesores, antiguos alumnos, salesianos y otros colaboradores externos.

De circulación gratuita y sin publicidad, su financiación dependió exclusivamente del propio presupuesto del Colegio. El modelo de dirección, gestión y organización no se explicitó en ningún número de la revista. Aunque contó con un equipo de colaboradores asiduos, no se conoce quiénes componen el equipo editorial encargado de supervisar los números, ni quiénes se encargan de corregir las aportaciones, más allá del propio Holgado que ejerce como director y redactor jefe. De entre las responsabilidades específicas destacaba la de cronista, función que recaía sobre un alumno de último curso de bachillerato y solía mantenerse durante todo el curso.

Por lo que respecta a los colaboradores externos, es difícil determinar si desempeñan algún papel en la gestación de la revista, más allá de la afinidad y amistad con Holgado, quien se encarga de coordinarlos. Es el caso de Cristino Lobillo, un antiguo alumno licenciado en ciencias químicas.

Manuel Morales, un activo miembro de la Asociación de Antiguos Alumnos y cronista oficial de Utrera ${ }^{10}$, publicará prácticamente en todos los números consultados, con trabajos de erudición en relación a temas de historia local y literatura, pero también aborda la crónica social y asuntos de actualidad. Para el número especial dedicado a Pío XII (n.o 5-6, 1943), escribe "La Iglesia y el Papa ante el derecho internacional", donde subraya el papel mediador de España en la resolución de la I Guerra Mundial. En la década siguiente, Morales, como fundador de la revista utrerana Cumbres, y otros

\footnotetext{
${ }^{9}$ En 1928, con ocasión de la visita a Utrera del sucesor de Don Bosco, Felipe Rinaldi, se imprime el folleto Recuerdo del curso 1927-28. Desconocemos si se trata de un anuario, aunque sin cabecera reconocible.

${ }^{10}$ Es un activo miembro de la Familia salesiana y debió mantener estrecha relación con Holgado desde su etapa de estudiante. Recibió premio de honor en el curso 1927-28 (Martín, 1981: 632) y en 1929 era secretario de la Asociación local de Antiguos Alumnos. En 1956, siendo ya cronista de la ciudad, con ocasión del 75 aniversario de la llegada de los Salesianos a España redactó los avatares de su establecimiento en Utrera (Martín, 1981: 765).
} 
antiguos alumnos salesianos trasladarán el proyecto y el estilo periodístico de Mi colegio (Montoya, 2022).

\subsection{Aspectos formales y diseño de la revista}

Mi Colegio es una revista mensual, aunque de salida irregular, suponemos que por las dificultades de edición con un sistema no profesionalizado. Entre abril de 1942 y marzo de 1945 se editaron 33 números, a razón de 18 números en el tercer año de la revista, 12 en 1943, 15 en el cuarto año. En el período de tiempo estudiado, la frecuencia de salida varía de mensual a trimestral, pero sin mermar en la calidad de la edición que paulatinamente va mejorando y ganando en presencia. De modo que evolucionó del folleto con noticias del colegio y el extracto de algunos trabajos escolares, a una revista con una línea editorial bien definida y una apuesta especializada en literatura e historia, con monográficos dirigidos por el director de la revista, José Holgado, que incluyen trabajos de investigación rigurosos y bien documentados.

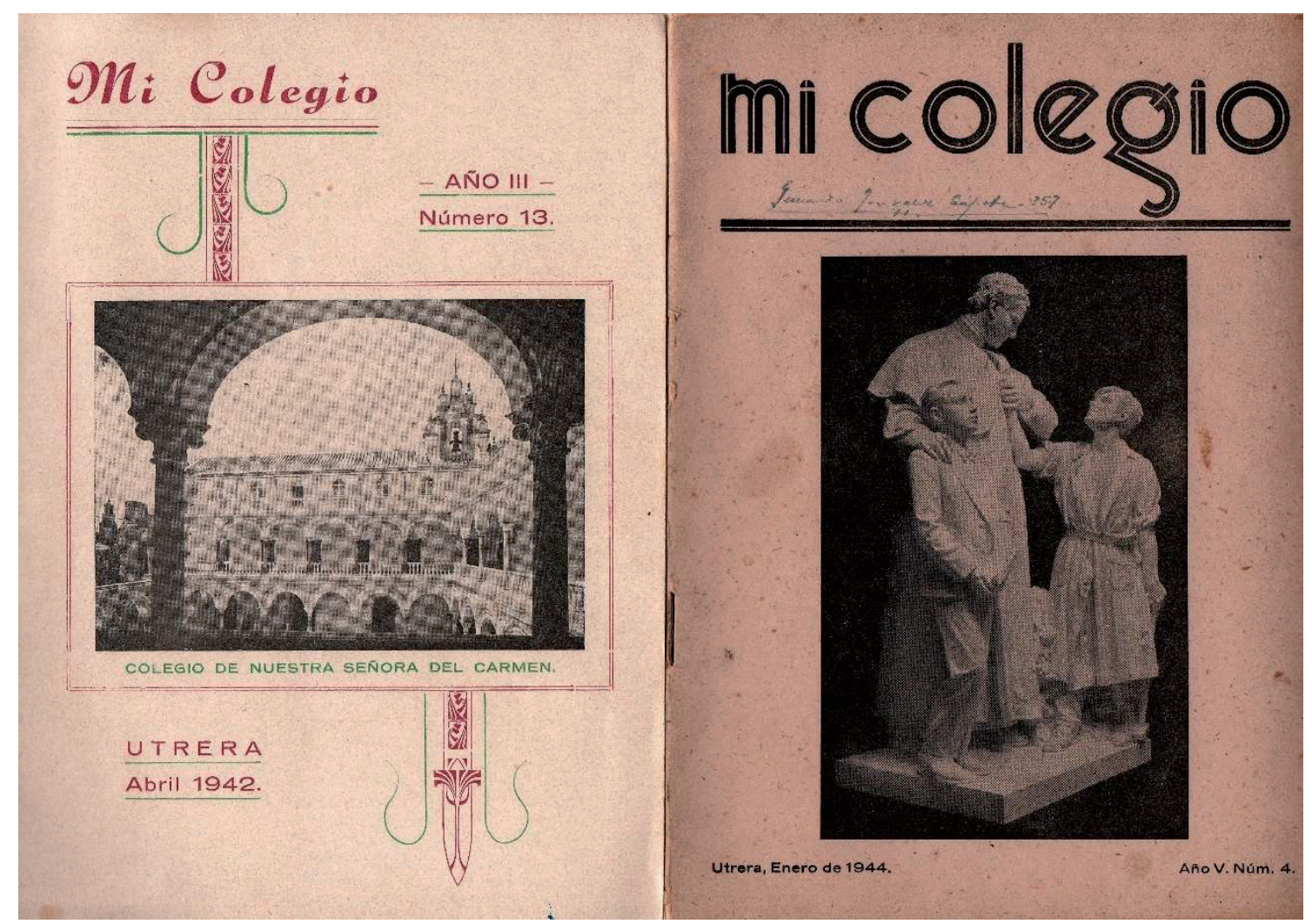

Figura 1. Evolución de las portadas de Mi Colegio. Año III, no 13, abril 1942 y año V, no4, enero 1944.

Mi Colegio salía con un pequeño formato arrevistado de $21 \times 15 \mathrm{~cm}$ con portada gráfica (figura 1) y una extensión variable entre las 24 ó 32 de los primeros números conservados, a las 44 páginas de media en la siguiente etapa, que viene a coincidir con el relevo en la dirección del centro. Cambia entonces también la calidad de impresión, pasando de imprimirse a dos colores (rojo y verde la portada; azul y marrón en el interior) y en un papel satinado de calidad, a otro más barato y tosco estéticamente en 
blanco y negro y un papel grueso. En el número de enero de 1945, la publicación, sin perder el formato arrevistado, aumentó su tamaño a $24 \times 17 \mathrm{~cm}$ y cambió algunos parámetros de diseño, volviendo al papel cuché en la portada, e introduciendo algunos tintes de color en la cabecera y algunos elementos más vanguardistas en las cabeceras de sección. Ya para entonces, que se había adaptado al formato monográfico, la revista aumentó considerablemente el número de páginas hasta las 60, 84 ó 182 que alcanza el número dedicado al teatro español clásico.

Tabla 1. Distribución temporal y de contenidos de la revista Mi Colegio (1942-1945)

\begin{tabular}{|c|c|c|c|}
\hline Años & № y fecha & Páginas & Tema principal del $n \underline{0}$ \\
\hline Año III 1942 & №13 abril & 32 & Domingo Savio \\
\hline “ & №14 mayo & 40 & $\begin{array}{l}\text { Entrega de premios anuales } \\
\text { y San Juan de la Cruz }\end{array}$ \\
\hline “ & $\begin{array}{l}\text { № } 17-18 \text { agosto y } \\
\text { septiembre }\end{array}$ & 24 & Historia del colegio \\
\hline Año IV 1942 & $\begin{array}{l}\text { № } 1-2 \text { octubre y } \\
\text { noviembre }\end{array}$ & 44 & Hispanidad \\
\hline “ & № 3 diciembre & 40 & Navidad \\
\hline Año IV 1943 & № 4 enero & 34 & Don Bosco \\
\hline “ & № 5 y 6 febrero y marzo & 52 & Papa \\
\hline “ & № 7 abril & 36 & Semana Santa \\
\hline “ & № 8 y 9 mayo y junio & 64 & $\begin{array}{l}\text { Entrega de premios anuales } \\
\text { y los conquistadores }\end{array}$ \\
\hline “ & № 10 julio & 44 & $\begin{array}{l}\text { Fiesta del Caudillo, Santiago } \\
\text { e Isabel la Católica }\end{array}$ \\
\hline “ & № 11 agosto & 40 & Sin tema principal \\
\hline “ & № 12 septiembre & 48 & $\begin{array}{l}\text { Los episodios nacionales de } \\
\text { Galdós }\end{array}$ \\
\hline Año V 1943 & № 1 octubre & 40 & Hispanidad \\
\hline “ & $\begin{array}{l}\text { № } 2 \text { y } 3 \text { noviembre y } \\
\text { diciembre }\end{array}$ & 64 & Navidad \\
\hline Año V 1944 & № 4 enero & 28 & Fiesta de Don Bosco \\
\hline “ & № 5 febrero & 44 & Sin tema principal \\
\hline “ & № 6 y 7 marzo y abril & 60 & Pasión y muerte de Jesús \\
\hline “ & $\begin{array}{l}\text { № 8-12 mayo a } \\
\text { septiembre }\end{array}$ & 182 & Teatro español clásico \\
\hline Año VI & $\begin{array}{l}\text { № } 2 \text { enero, febrero y } \\
\text { marzo }\end{array}$ & 84 & Literatura latina \\
\hline
\end{tabular}


En lo relativo al diseño, la revista sigue el paradigma de las revistas de calidad para la infancia y los jóvenes (Chivelet, 2011). Comparándolas a nivel estético, aquellas con portadas de diseños exclusivos, tipografías llenas de movimiento y libertad, dinamismo y plasticidad, Mi Colegio resulta, pese a su cuidada presentación, un producto sobrio. Frente al atractivo visual, esta revista escolar prima lo textual, pensada para ser leída e incluso, para convertirse en material de consulta para los alumnos, con artículos de fondo y datos de divulgación que pueden ayudar en la tarea de estudio cotidiana.

Los elementos gráficos y visuales, por tanto, no son determinantes en la publicación, aunque en ocasiones se incluyan fotografías, reproducciones de obras artísticas o mapas y otros materiales de apoyo, como mapas (figura 2) o tablas.

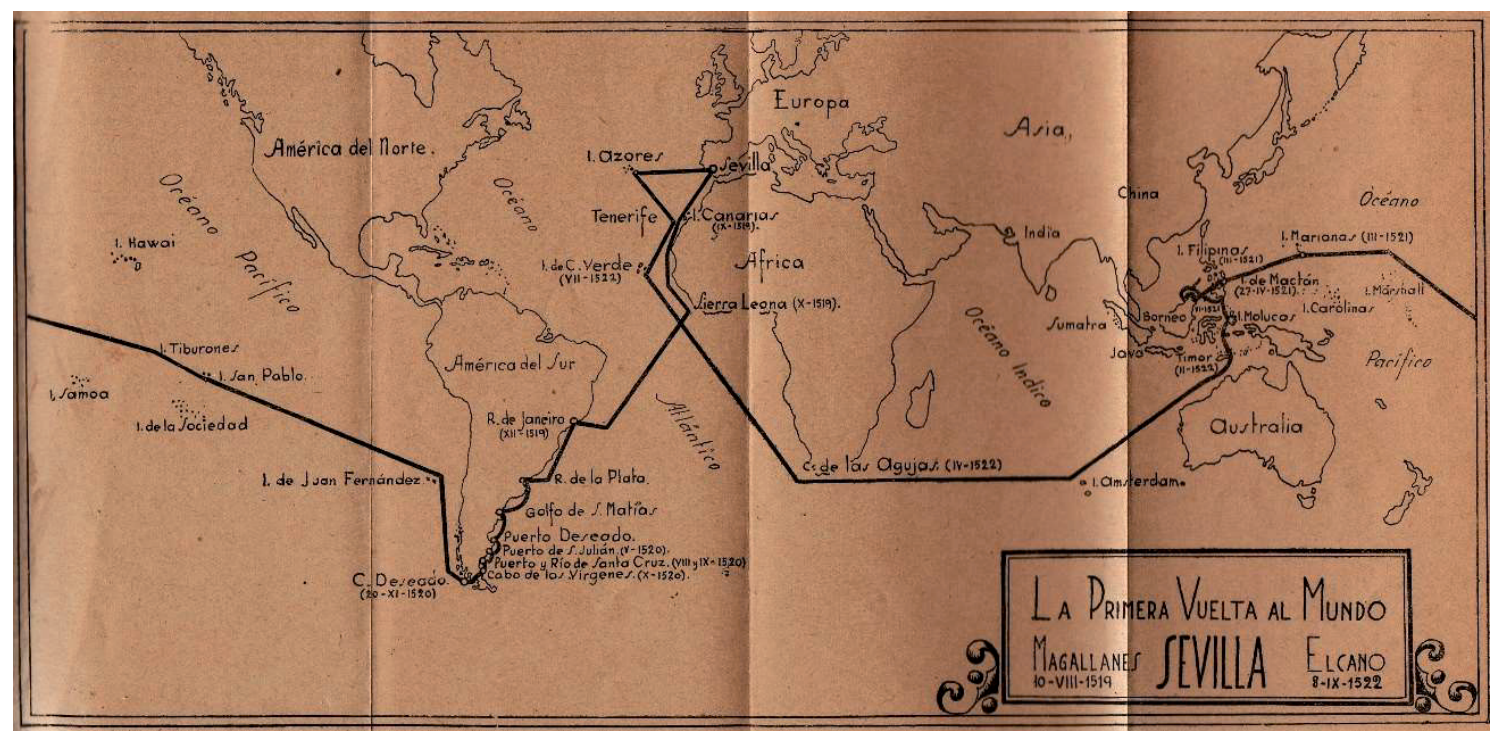

Figura 2. Mapa desplegable sobre la primera vuelta al mundo no 1 y 2, octubre y noviembre 1942.

Como carta de presentación de la institución, las fotografías de portada hasta los números de febrero y marzo de 1943, reproducen exclusivamente vistas o espacios arquitectónicos del propio colegio vacíos (Patio de Fiestas, patio central, sala de visitas y las huertas). A partir de esa fecha se incluyen también fotografías de espacios singulares del patrimonio monumental utrerano (Paseo y Santuario de Consolación). Ocasionalmente ocuparán la portada también los retratos de Don Bosco ( $n$ o 4, 1944), del Rector Mayor de los salesianos, Don Ricaldone (no 7, 1943), o de Menéndez Pelayo (no 8-12, 1944) presentados como referentes espirituales e intelectuales, respectivamente. Para los números dedicados a los tiempos litúrgicos de la Navidad o Cuaresma y Pascua, se recurre a imágenes artísticas con escenas navideñas ( $n$ 2-3, 1943) o de la Santa Faz (no 6-7, 1943) y Jesús Orante de Berruguete (no 5, 1944).

Por lo que respecta al interior de la publicación, la sobriedad y el gusto preferente por la imagen artística también son las notas dominantes. Los artículos de contenido 
religioso se ilustraban con series de estampas de vidas de santos, fotografías de la imaginería cofrade, con una estética neobarroca que busca captar los afectos. Mucho más interesante resulta la reproducción de obras de arte, pintura, escultura o arquitectura, que acompañan a los temas literarios e históricos, que elevan la percepción del lector sobre los textos, con un discurso paralelo que merecería un estudio en mayor profundidad.

Sólo ocasionalmente se recurre a la fotografía informativa de actualidad. Se incorporan a la sección fija de crónica que abre la publicación, tras la carta del director, y a otros espacios ocasionales donde se relatan los eventos, actos sociales y culturales y otros acontecimientos de la vida académica: escenas de la vida colegial, de excursiones o actos académicos. Suelen ser fotografías protocolarias, posados en las instantáneas de grupo, y por tanto exentas de naturalidad y espontaneidad rehuyendo de todo protagonismo y personalismo y relegando la imagen humana a un segundo plano. Tienen dimensiones reducidas que se acomodan al formato pequeño de la revista, sin restar protagonismo a los textos. Algo mayor son las fotografías de los cursos que se incluyen en los números de final de curso, junto a los cuadros de honor de quienes han recibido algún premio o distinción académica.

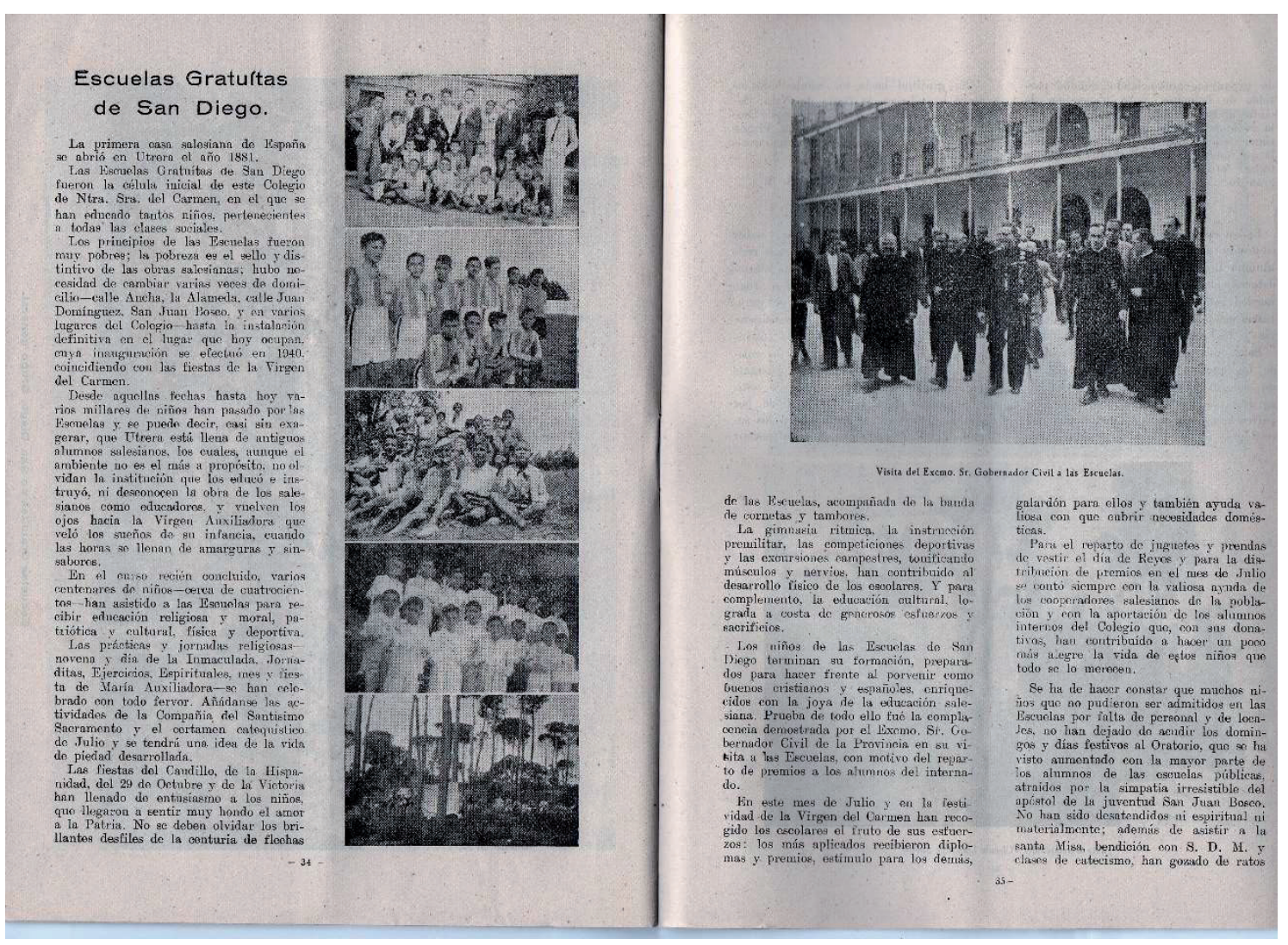

Figura 3. Crónica sobre la visita del Gobernador civil a las Escuelas de San Diego, nำ10, julio 1943.

Sobre la estructura de la publicación el análisis revela que no había secciones fijas más allá de la carta del director, la crónica escolar y la sección de Amenidades y pasatiempos 
que cerraba la revista. El resto de la publicación no tenía estructura estable y se iba diseñando número a número según necesidades temáticas puntuales. También era fijo el apartado de colaboraciones de los alumnos pero estas variaban en número, temática y extensión. Convivían las creaciones inéditas hechas ex-proceso para la revista, posiblemente por encargo o dirigidas, junto a otras colaboraciones fruto de tareas escolares. Los había de naturaleza poética o narrativa, y entre estas las había de temática literaria, histórica, y también los de investigación sobre asuntos artísticos, o de carácter experiencial. También las crónicas de actividades académicas.

Por lo general, las páginas donde se publican trabajos de los alumnos suelen tener una disposición más ágil en cuanto al diseño, con una temática más variada, un tono más ligero y una redacción algo más desenfadada, sin desdecir la seriedad característica de la revista.

\section{Contenidos y líneas temáticas}

En este apartado se aborda la descripción de los contenidos identificados en el análisis y su organización en secciones, así como aspectos redaccionales como el uso del lenguaje y los géneros empleados.

Por lo que respecta a la concepción de la revista, más que en términos informativos, como memoria viva del acontecer del colegio, la revista fue concebida como una publicación divulgativa. Esto tiene bastante que ver con la impronta personal de su director, José Holgado que, a decir de los alumnos, es poco amante de la crónica frívola, "del bombo y la propaganda" y suprime todas las manifestaciones emotivas en sus colaboraciones (no 6-7, 1944: 4).

Suele recurrirse más a la crónica que a la noticia, que muy rara vez se utiliza. En la sección Crónica, realizada por un alumno fijo, suele recurrirse al género epistolar, dando lugar al intercambio de pareceres y confidencias sobre la vida escolar. En ocasiones la comunicación se torna intimista cuando se narran vivencias personales, se profundiza en el testimonio de vida o se adentra en el terreno vocacional. Se consienten ciertas licencias de estilo libre, alguna queja quizás a las rigideces del reglamento y los exámenes, pero rara vez la crítica. Por ello sorprende que Holgado haya dejado que se deslicen algunos fragmentos críticos contra el rigor del nuevo modelo de Bachillerato y los exámenes de revalida.

Los alumnos también colaboran aportando sus creaciones literarias, ya sea en forma poética o ensayística; otras, muy frecuentemente, son propuestas por Holgado, de tema libre o pactado. Estos textos juveniles tienen naturaleza divulgativa sobre asuntos 
científicos, explicados en las aulas o fruto de la investigación particular, y merecen un estudio más detallado que permita adentrarse en la asimilación de los contenidos propuestos en el proyecto salesiano. De esta manera, los contenidos de la revista son una extensión del currículo oficial de las materias científicas que se imparten en Bachillerato: con artículos sobre química, lenguas clásicas y, particularmente, de historia y literatura española. Excepcionalmente, los salesianos de la comunidad educativa colaboran con textos de espiritualidad o de temática específicamente salesiana.

Completan los contenidos de Mi Colegio los artículos de fondo o trabajos de investigación tomados de otras publicaciones periódicas sobre variadas temáticas (filosofía, teología, pedagogía, ...). Con ello la revista hace accesibles los avances en las distintas disciplinas al alumnado y a un público popular. Se trata de acercar los grandes temas de debate de la realidad nacional, con especial protagonismo de aquellos que ayudan a la configuración de un ideario franquista. Cabe destacar, en este sentido, la inclusión de textos de literatos y pensadores, con preferencia por los que han combatido las desviaciones liberales (José Mạ Pemán, Ramiro de Maeztu, Rodríguez Marín, Alarcón, Manuel Machado...). A partir del quinto año, se introduce la sección Antologías donde se reproducen íntegramente discursos, conferencias, cuentos y fragmentos literarios de autores actuales o textos periodísticos de difícil acceso para el escolar. Abre la sección el discurso del Caudillo en la inauguración de la Ciudad universitaria de Madrid (no 2 y 3, 1943).

En el número de verano de 1944 y durante el curso 1944-45, la revista da un cambio de rumbo con un planteamiento monográfico que supone un salto cualitativo en la calidad de la revista y un impulso definitivo a la propuesta divulgativa ya apuntada. Por lo que respecta a las temáticas, se abandona la centralidad de los de naturaleza histórica y cobran fuerza las del ámbito de especialización de Holgado, la literatura española: el teatro romántico español, en el primer monográfico, y los vínculos de España y la cultura romana, en el segundo. El punto de partida son trabajos académicos que resultan de investigaciones dirigidas y de una encomiable revisión bibliográfica. Los textos se redactan con un planteamiento divulgativo. El resultado es una publicación de calidad, especializada en cultura. El monográfico sobre el teatro romántico español (no 8-12 de 1944) contó con treinta y cinco trabajos, casi todos ellos realizados por alumnos de 60 y 70 de bachillerato, además de otros colaboradores como Manuel Morales. Lo mismo cabe decir del segundo monográfico ( $n$ - 2, 1945), donde José Holgado colabora con cuatro trabajos: "España en Roma", "Itálica en la literatura", "Séneca" y "Cristus vincit". Seguramente, el cambio vino motivado por una promoción especialmente entregada y diligente en su asignatura como parece atisbarse en la dedicatoria que les hace (la única en todos los números): "a mis amigos de séptimo curso 1943-44 como recuerdo de una larga convivencia por los campos de la historia y de la literatura". La relación de confianza mutua entre el educador y el discente es una de las claves del sistema preventivo de Don Bosco. 


\section{Buenos cristianos, honrados ciudadanos}

Abordamos en este apartado los resultados de la investigación relacionados con la línea editorial que sostiene la revista, en primer lugar, en relación al modelo de persona de la propuesta educativa salesiana y, en segundo lugar, en relación con la función social que ha de desempeñar la juventud en el contexto histórico nacional y mundial.

\subsection{Valores humanos y valores cívicos}

La propuesta de valores humanos y cívicos puede seguirse en la revista a través de los textos que de forma recurrente publicaron los salesianos de la casa, fundamentalmente José Sánchez, el director del centro que dirige en cada número unas palabras a los alumnos a modo de editorial, y el director de la revista, José Holgado. Otros salesianos, como José de Alba, colaboraron con poesías o artículos especializados en distintas materias.

La sección de carta del director es un ejemplo de comunicación uniforme, centralizada desde arriba y sometida al principio de autoridad. A través de la lectura de estas cartassaludo, al modo de la herramienta pedagógica conocida como los "Buenos días" o las "Buenas noches" -una charlita o reflexión motivacional al iniciar o finalizar el día con breves consignas-, podemos identificar la línea pedagógica y evangelizadoracatequética y el ideario de este centro educativo.

Con un estilo directo y sencillo, el discurso está lleno de ejemplos, consignas morales, fácilmente recordables y adaptables a infinidad de realidades cotidianas. Aunque los temas preferentes son la convivencia, la disciplina, la marcha del curso o los ciclos litúrgicos, se abordan otras cuestiones relacionadas con la actualidad y los problemas sociales.

Son frecuentes las referencias al momento histórico que vive España, sin referencias políticas explícitas. La defensa cerrada de patria y de los nuevos presupuestos que fundamentan el Estado van a ser una constante. Así, en su despedida como director de la Casa Salesiana, Manuel Fernández recomienda a los alumnos mantenerse a salvo de la "corrupción general" para así convertirse en "un paladín de la fe y un baluarte de la España grande y tradicional”. Su sucesor, Claudio Sánchez es bastante más comedido en sus afirmaciones, pero también enfrenta a los alumnos al doble compromiso cívico y cristiano, ambos ineludibles, que deben asumir:

Vivís en época difícil, de encontrados y opuestos ideales. La patria exige la decisión y el sacrificio a sus hijos, la Iglesia reclama la imitación leal y franca de Jesucristo, cristianos de nombre y de hechos. (no 4, 1944: 3). 
El combate contra las fuerzas contradictorias exige estar alerta en todo momento, según la propuesta educativa que Sánchez traduce en estas cartas. Y no cesa de recordarlo de muchas y variadas maneras. Igual que no caben medias tintas en el asunto del seguimiento de Cristo, tampoco caben en el ejercicio de los deberes ciudadanos:

Sed apóstoles. Apóstoles del buen ejemplo en vuestros hogares y relaciones de sociedad. Apóstoles de la palabra en la delicadeza de vuestras conversaciones y la prudencia de vuestros consejos. Apóstoles de la verdad: ivenced el respeto humano y no permitáis jamás que delante de vosotros se diga, sin vuestra réplica inmediata, lo que repugna a vuestras conciencias de cristianos, y de alumnos de un colegio salesiano. ( $n$ ㅇ 10, 1943: 3).

Incide en estas ideas el director de la revista, José Holgado, en un artículo sobre la vocación y los espacios para la libertad, previniendo a los alumnos de los grandes peligros de unirse a la masa, de seguir las modas, y también de ceder a los grandes enemigos de la patria: "No seréis libres si la revolución y la anarquía son los dueños de tu corazón; si el pecado y el vicio son huéspedes indeseables de tu alma" (no 17-18, 1942: 7).

\subsection{Referentes para los jóvenes}

Los referentes para las nuevas generaciones, según la propuesta de Mi Colegio, se encuentran en la historia de la Iglesia y en la propia congregación salesiana, pero también en la cultura patria y los iconos de la nación: Santiago, los conquistadores, Isabel la Católica,... Sólo excepcionalmente señaló la revista al dirigente del Estado como un referente para los jóvenes, a pesar de que en los años cuarenta aún se conservan muchos de los presupuestos fascistas de exaltación del líder. Son contadas las referencias al Caudillo, especialmente en los números consagrados a la Fiesta de la Hispanidad y a repensar el papel histórico, de signo universalista, que le corresponde desempeñar a la juventud. Así, Claudio Sánchez, muy sobrio en sus manifestaciones políticas, conmina a los alumnos en la carta de inicio del curso 1942-43 a seguir la consigna de la Patria que el Caudillo ofreció a los cinco mil jóvenes reunidos en El Escorial, exhortándoles a ser "viriles y heroicos hacia el exterior, generosos y virtuosos en el interior" (1942, nำ: 3).

Holgado, por su parte, se deshace en elogios al Caudillo en el artículo "18 de julio" en el número de julio de 1943 por su "justeza, acierto y dirección providencial" en los envites de la guerra para que España vuelva a ser "el brazo robusto de la Iglesia, la atalaya siempre alerta de la civilización occidental y el debelador del acoso" (1943, no10: 8). En octubre se inaugura la sección Antologías con la reproducción del discurso íntegro de Franco en la inauguración de la Ciudad Universitaria de Madrid (1943, no1: 10-12). La última referencia al caudillo la encontramos en el trabajo de un alumno escrito en 
italiano que lo considera "il uomo migliore" e "il vero capo della Rivoluzione" (1942, no17-18: 18) -el mejor hombre y el líder de la revolución-.

Entre los modelos vitales que se ofrecen a los jóvenes los religiosos se anteponen a los líderes políticos e ideológicos, como puede comprobarse en este texto del salesiano S. García, donde considera que la responsabilidad de los directores de colegios salesianos es "mayor aún que los problemas de un jefe de Estado" (1943, no 12: 22) preocupados por convertir a los antiguos y presentes alumnos en "glorias para la Iglesia y para la Patria".

\subsection{Cristianizar España y defender la Hispanidad}

En los números dedicados a la fiesta de la Hispanidad se incluyen artículos dedicados a explicar la misión sagrada que corresponde a la Iglesia del momento: volver a cristianizar la historia de España. El director de la revista concreta esta misión en artículos como “Cruz y espada” (1942, № 1-2: 8) y “iAmad a España!” (1943, no 1: 7-9). El mundo, según Holgado, se encuentra "en un callejón sin salida" y le corresponde a España una misión salvífica igual que en tiempos remotos "detuvo el empuje del islam, rasgó las barreras del mar tenebroso, humilló las águilas triunfantes de Napoleón y deshizo los rojos batallones del crimen de la traición y la alevosía". La Iglesia la reclama para "reconquistar para la cruz pueblos que un día se alejaron de su regazo". En esa misma reconquista deben empeñar sus fuerzas los alumnos, reconquistando "ovejas descarriadas" que, aunque bautizadas, son "esclavos del demonio". $Y$ les recomienda trabajar "ahincadamente" para que España vuelva a ser "castillo de la fe y baluarte de la catolicidad" (1943, no 1: 7-9). Y en otra ocasión les invita a sumarse a esta misión en estos términos:

Forjad la decisión, robusteced el empeño y afianzad el juramento de no cejar hasta conseguir con el esfuerzo del brazo, la energía de la inteligencia y el vigor viril del alma que España vuelve a caminar por los senderos de Cristiandad y de Imperio que la hicieron un día baluarte de la Iglesia y madre de pueblos y naciones. (1943, no10: 9).

El hecho central en la historia de España es el descubrimiento y conquista del continente americano, que Dios le concedió “como premio a la fidelidad" (1942, no 1-2: 8). De modo que Holgado no duda en arremeter contra cualquiera que contradiga este pasado glorioso, como Bartolomé de las Casas, que resultó ser un "español equivocado" (1943, no 8-9: 27) por su enfoque crítico:

(Casas) engranda las pequeñas impurezas del presente y con lente de aumento, y en su loco afán pesquisidor aumenta cifras, añade guarismos y hasta inventa de la nada crímenes, abominaciones y desastres. Lamentable pero fenómeno hasta 
comprensible en ese fraile bronco, inadaptado, fuera de la realidad, que sueña con absurdas quimeras.

También Holgado se atrevió a poner bajo sospecha a Hernando Colón, a quien se acusa de flagrante parcialidad a favor de su padre en sus escritos sobre la conquista y su "encubierto antiespañolismo" en razón del ataque que lanza contra los Pinzones, la mayoría de los colaboradores de Colón y de las "especias desfavorables" que desliza contra Fernando el católico.

En relación con la población nativa americana por España, justifica la relación de superioridad establecida: "[España] blanqueó los rostros atezados de los negros y arrancó de la selva y de la holganza al árabe indolente y al indio bravo y luchador" (1942, no 1-2: 8) y "no dudó en mezclar su sangre con la de los pueblos aborígenes para blanquear sus carnes atezadas e introducirlos en el redil de Cristo" (1943, no 8-9: 19). Y es precisamente esa inferioridad del indio la que le permite justificar incluso el uso de la fuerza con ellos:

...al chocar con los indios ni humildes ni mansos, sino aguerridos y fieros casi siempre, al verse (los españoles) rodeados por una naturaleza donde cualquier descuido era mortal y donde la crueldad y la muerte les acechaban, no es extraño que sus corazones se endurecieran y el instinto de la propia defensa los empujara a saltar las barreras de la justicia y a despreciar al llamamiento de la piedad, cometiendo entonces desmanes o enzarzándose en tropelías. (Mi Colegio, 1943, no 8-9: 19).

Igualmente, los trabajos de los alumnos situaron a los naturales en franca desventaja ante la superioridad de los españoles. En un artículo sobre Hernán Cortés donde se desmiente a los historiadores malintencionados que acusan al personaje de crueldad y de cometer injusticias, se responde categóricamente con un contundente: "ello es absolutamente falso, la culpa fue de los indios".

\section{Discusión}

Este estudio de caso busca contribuir desde una perspectiva local a los aportes sobre las revistas escolares en la etapa del primer franquismo que han realizado otras investigaciones sobre revistas jesuitas de Valencia (Lull, 1999) y Mallorca (Moll y Sureda, 2021). La revista Mi Colegio se inscribe, en cambio, en la política editora de los salesianos en España lo que le confiere especiales matices y connotaciones dentro de las conclusiones planteadas por estos estudios. Esto obliga a una revisión teórica de la aportación de la Sociedad San Francisco de Sales a la historia de la educación y de la 
Iglesia en España (Alberdi, 1994) y de la propia publicística católica. El hecho de que la Sociedad dispusiera de talleres-imprenta permitió, en un tiempo de escasez de libros e impresos pastorales y catequético, la producción de obras para la educación de los jóvenes como la Biblioteca de Lecturas de la Librería Salesiana. De otra parte, la propia experiencia en el campo de la comunicación social alentó nuevos proyectos periodísticos en la posguerra como la edición española del Boletín salesiano, en 1944.

Editada en las Escuelas Salesianas de Artes Gráficas de la Trinidad (Sevilla), esta publicación se inscribe en esta línea, heredada de Don Bosco, de proveer de lecturas que ahondan en diversas líneas preferentes o directrices: primeros siglos del cristianismo, misiones católicas entre infieles, vidas ejemplares de santos (particularmente salesianos), hazañas de héroes y obras dramáticas y de diversión (Vilanou y Villafranca, 2020: 299). Las líneas temáticas de la publicación continúan esta apuesta editorial, que se completa con colaboraciones de antiguos alumnos con textos sobre historia, literatura y ciencia y la reproducción antológica de autores clásicos. Mi Colegio fue concebida como una publicación para la extensión del conocimiento y una herramienta complementaria a la formación reglada, con un concepto del saber enciclopédico y memorístico.

Como balance de la investigación subrayaremos el valor de esta revista, sobre la que aún no se habín acometido estudios, para el estudio de la prensa escolar. El perfil corporativo de las revistas escolares (Campos, 1995) es más manifiesto en el modelo jesuita. Las revistas cumplen una función de coordinación que aglutina, amplifica y da coherencia al conjunto de organizaciones que constituyen la comunidad educativa del centro (Moll y Sureda, 2021). El estudio de caso de Mi Colegio revela que esta función no es prioritaria, aunque ocasionalmente se conviertan en protagonistas la Asociación de Antiguos Alumnos, la Archicofradía de María Auxiliadora o los distintos grupos pastorales y catequéticos que se desarrollan su actividad en el colegio de Utrera. Tanto es así que ni siquiera las escuelas gratuitas de San Diego están representadas más que de forma minoritaria en la revista, siendo la infancia obrera y desvalida la preferida de Don Bosco y sobre la que construye toda su propuesta de pedagogía social. El protagonismo de los bachilleres, por el contrario, confirma el concepto elitista de educación que rige al colegio en ese momento histórico.

Es, en cambio, la divulgación de trabajos escolares la auténtica finalidad de la publicación, ya sean estos realizados como actividad académica o por encargo, que adquieren incorporados a un producto mediático, una dimensión profesional. Se completa así el paradigma de la pedagogía de Don Bosco de atender todas las dimensiones de la persona. La periodística es una tarea complementaria a la formación reglada, que permite a los alumnos descubrir otras habilidades socio-profesionales que no pueden ejercitarse en la rigidez del plan de estudios del bachillerato franquista. De acuerdo con la propuesta de Waidenfeld (2012), la revista Mi Colegio se presenta como 
un instrumento pedagógico más del sistema impulsado por Don Bosco: el sistema preventivo. En este sentido, todas las actividades que se desarrollan en el centro, tanto en la educación formal como informal, deben servir a la formación integral del alumnado. Un alumno que presenta como un ser voluble y tendente al pecado y al que se le propone como ideal de vida una subordinación absoluta de los derechos personales, y de la libertad, en favor del bien general y los intereses de la comunidad y el Estado. Sin embargo, más que por un método correctivo y represor, cercano a los modos de exhortación propagandísticos (Bordería, 1996), los salesianos responsables de la revista apuestan por el modelo pedagógico de Don Bosco, el sistema preventivo, que instruye y prepara a la persona para evitar su perdición.

Lo preventivo es sinónimo de promoción social, entendida esta como una completa capacitación de la persona en todos los ámbitos de vida (Bastida, 2012). En los años de postguerra Rodolfo Fierro se encargó de realizar un estudio sistemático sobre la pedagogía social de Don Bosco y a presentarlo como un prototipo en el mundo católico, una dimensión apologética que el nacionalismo propició. Se subrayan, así, las capacidades del educador salesiano como un acompañante que previene con avisos amistosos y preventivos, como un bienhechor que está de parte del joven (Fierro, 1950). Esta pedagogía, esencialmente pastoral, no sólo tiene su aplicación en el plano académico, sino que se traduce en un discurso mediado como es el periodístico. La revista en sí, y particularmente los textos de los salesianos -cartas del director y las colaboraciones de Holgado- adquieren esta dimensión preventiva.

Finalmente, Mi Colegio no tiene una intencionalidad comercial ni fines lucrativos tan explícita como ocurre en el caso de las publicaciones jesuíticas (Moll y Sureda, 2021), aunque la propia existencia de la revista redunda en beneficios para el colegio. Los medios de autopublicidad son más sutiles que en las publicaciones corporativas: las fotografías de las portadas promocionan las instalaciones; la actitud de acogida y atención personalizada del director del centro y del director de la revista son la mejor promoción para el ideario y el proyecto educativo; los reportajes sobre actos académicos, con destacados personajes de la vida pública, son la mejor garantía para las familias de una red social e institucional de protección para el centro y sus alumnos; la cultura del éxito que exaltan los reportajes sobre entregas de premio son la mejor política de captación del alumnado; y, finalmente, la inclusión de testimonios de antiguos alumnos que triunfan en lo profesional o en su opción por la vida religiosa, fortalece la confianza de los alumnos y sus familias en la fiabilidad del proyecto educativo salesiano.

Los salesianos, alentados por el ejemplo de Don Bosco, incorporaron a la propuesta educativa de sus centros la creación de medios de comunicación, para estimular la creatividad, favorecer el aprendizaje social y generar una cultura de la participación ciudadana. Dado el carácter pionero de Mi Colegio en la prensa escolar de la posguerra 
en la provincia de Sevilla, su modelo y su línea editorial posiblemente tengan continuación en otras publicaciones escolares de la provincia. Habría que confrontar además el modelo de masculinidad propuesto en las revistas de los centros para niños con el modelo de los centros femeninos, como en Regina Angelorum (1952), revista del colegio de las Irlandesas de Castilleja de la Cuesta. Es una hipótesis que queda para futuros trabajos, así como el análisis de otras revistas editadas por los salesianos de Utrera en la década de los cincuenta: Llamada, del Estudiantado Filosófico salesiano, y Consolación, una hoja informativa que promueve la devoción a la patrona, la Virgen de Consolación.

Por lo que respecta a la relación de la publicación con su entorno, conviene completar el estudio en la perspectiva del periodismo de proximidad. Trabajos como el de Yanes (2004) o Hernández (2017) abordan el fenómeno de la prensa escolar desde la perspectiva más amplia del periodismo local y su imbricación a su vez en los procesos de cambio político y social. Los resultados de esta investigación abren nuevas vías para un ámbito muy poco estudiado, el periodismo en la provincia de Sevilla, donde proliferarán durante el primer franquismo otras revistas culturales (Checa, Espejo, Langa, Montoya, 2022), similares en concepto y planteamiento a Mi Colegio, particularmente las utreranas Cumbres y Vía Marciala (Montoya, 2022). Estas otras investigaciones permitirían valorar su contribución en términos periodísticos.

\section{Conclusiones}

La principal aportación de este trabajo es la recuperación de una fuente primaria para el estudio de la prensa escolar en esta etapa de cambios y recuperación como es la revista Mi Colegio, sobre la que aún no se habían desarrollado estudios específicos. Presenta un modelo de revista divulgativa que difiere en algunos matices de los proyectos de revistas escolares jesuitas, más informativas y con fines corporativos y publicitarios más explícitos.

El estudio de caso nos ha permitido identificar una cultura escolar elitista del centro que lleva a priorizar informativamente las necesidades de los alumnos de bachillerato, sobre otras realidades educativas y pastorales de la vida del centro, como las escuelas gratuitas o las asociaciones eclesiales que, a la larga, dispondrán sus propias publicaciones, como la hojita informativa que imprimirán los Antiguos Alumnos. La vida cotidiana gravita en torno a este alumnado, proveniente de las grandes familias de clase media que pueden permitirse pagar por una educación de calidad. La proyección social de estos alumnos, llamados a convertirse en profesionales liberales, se consigue ampliando sus horizontes vitales y cultivando las relaciones sociales, particularmente 
estrechando los lazos con los antiguos alumnos y con profesionales de referencia y las autoridades que visitan con frecuencia el centro. De toda esta cultura organizativa dan cuenta las crónicas y las colaboraciones en la revista, que hacen visible este escenario de relaciones favorecedoras

La revista, además, impulsa las capacidades del alumnado, las exhibe y las proyecta hacia un universo de adultos, representado por las familias, que perciben los méritos de sus hijos y los frutos de su esfuerzo, y hacia el entorno, con una cultura del reconocimiento y el triunfo muy cercano a la propuesta educativa de otras escuelas confesionales, como las jesuitas, durante la posguerra.

Era un objetivo de partida comprender la propuesta educativa salesiana en el marco de la posguerra, como respuesta al proyecto de Don Bosco, y en relación con la reconstrucción de la identidad nacional. En este sentido, Mi Colegio ejemplifica fielmente el sistema preventivo salesiano, con un concepto negativo de persona llamada a pecar pero que es salvable con el apoyo de un acompañante-educador que le advierta de los riesgos. Particularmente, en un contexto como el de la posguerra, se previene contra el libertinaje, la anarquía y los enemigos de la religión y la patria.

Ha quedado confirmada la finalidad es preferentemente divulgativa de esta revista salesiana, frente a otros modelos de publicación escolar, como el jesuita, más orientado a la cohesión de la comunidad educativa y a otros grupos pastorales y asociativos. Mi Colegio cumple la función de facilitar y reforzar las relaciones de los padres y los antiguos alumnos con el centro, fomentando la cohesión y creación de un sentido de pertenencia a la familia salesiana. El resto de grupos apenas tienen representatividad, de lo que resulta un producto periodístico para las elites.

El perfil catequético y el afán evangelizador, cuando no adoctrinador, definen en el espacio de la comunicación social de Mi Colegio. Este carácter de herramienta al servicio de los intereses eclesiales no es argumento suficiente para desconsiderar su valor periodístico y su contribución al servicio de la formación de la conciencia ciudadana de los alumnos, de sus familias y, en general, del propio entorno del colegio de Utrera, donde el centro desempeña una función de referencia cultural. El público lector de la revista es variado y popular, de toda clase, formación y condición, aunque el eje de intereses, como se desprende por la selección de contenidos y la apuesta por la divulgación de asuntos literarios, históricos y científicos, gravite, especialmente, en torno a los alumnos de las familias de los internos que sostienen económicamente el centro.

La investigación ha revelado nuevas interrogantes que la localización de nuevas fuentes hemerográficas y documentales podrá solucionar. Es particularmente urgente ampliar la muestra de estudio con los números de 1939 a 1942 que permitan aclarar si las características periodísticas y las líneas temáticas se confirman. Puesto que, a medida 
que la revista se va consolidando, cobran fuerza los contenidos culturales y se desecha la línea argumental que la vincula con los intereses del Estado, la hipótesis es que los primeros números (1939-1942) están más supervisados por las autoridades franquistas y el discurso fascista estará más presente, particularmente en torno a la recristianización de España y el papel histórico de la Iglesia. De este modo, en el microcosmos que representa este colegio salesiano, en la campiña sevillana, encontrarán acomodo las directrices, ideas y valores cívicos propuestos por el primer franquismo. Para el período estudio, estos contenidos ya no tienen un protagonismo absoluto frente a la propuesta evangélica y salesiana que el centro representa. La revista es muy comedida en el uso de simbología y elementos icónicos fascistas, tan abundante en la prensa de la época. Sólo dos elementos le otorgan un cierto perfil de publicación afín al régimen: la inclusión de textos de autores de referencia en el primer franquismo como Ramiro de Maeztu, José María Pemán o Manuel Machado y la dedicación de los números de julio y octubre a fomentar las ideas patrióticas, a conmemorar al Caudillo y presentar el descubrimiento de América como el hecho fundante de España y de su proyecto católico de nación.

Mi colegio defiende un modelo de educación nacional al servicio de las necesidades del Estado, más que del Caudillo, cuya figura no es protagonista de la revista ni es motivo central en la propuesta salesiana. Antes bien, el análisis de los textos de contenido histórico, y particularmente de los que abordan el asunto de la Hispanidad, nos permite constatar cómo se anima a los alumnos a ser colaboradores en la reconstrucción de la patria y el compromiso activo de un cristianismo militante. Sorprende, sin embargo, la ausencia total de referencias a la Guerra Mundial y a la resolución de conflictos entre las naciones salvo en el número dedicado a las bodas de oro sacerdotales del Papa. Los problemas de España se anteponen a los de la humanidad y se releen a la luz de la misión histórica que Dios le tiene encomendada: la recristianización del mundo.

\section{Referencias bibliográficas}

ÁLVAREZ GONZÁLEZ, Luis Fernando, "La Asamblea Nacional del D. Bosco en España", Don Bosco en España, n. 735, marzo-abril, 2018, pp.6-7.

BASTIDAS, J. y PAUCAR, E. (2012), El Sistema Preventivo de Don Bosco. Quito, Imprenta del Colegio Técnico Don Bosco

BORDERÍA ORTIZ, E., MARTíNEZ GALLEGO, F-A, LAGUNA PLATERO, A (1996), Historia de la comunicación social: voces, registros y conciencias, Síntesis.

CAMPOS GARCÍA, JUAN JESÚS: «El periódico escolar: un acercamiento a la cultura organizativa del centro», en Comunicar, no 5, 1995, p. 113-119. 
CHECA GODOY, A. (2002): Historia de la prensa pedagógica en España, Universidad de Sevilla.

CHECA GODOY, A. LANGA-NUÑO, C. y ESPEJO-CALA, C. (coords.), MONTOYARODRÍGUEZ, C. (ed.) (2022) Historia del periodismo local en la provincia de Sevilla. Contra el olvido de la prensa cercana, Granada, Ed. Comares (en prensa)

CHIVELET, M. (2011), "El diseño de revistas para los niños, exponente de su evolución en el entorno social”, en Pérez Cuadrado, P., Puebla Martínez, B. (coord.), Revistas versus magazines, pp. 65-74.

DELGADO GRANADOS, P. (2010), “Una mirada al modelo escolástico franquista a través de sus revistas escolares: fuente de estudio e interpretación histórico-educativa" [en línea]. Cabás: Revista del Centro de Recursos, Interpretación y Estudios en materia educativa (CRIEME) de la Consejería de Educación del Gobierno de Cantabria (España), o 3. Disponible en Internet (17-8-2021): http://revista.muesca.es/articulos3/130-una-mirada-al-modelo-escolasticofranquista-a-traves-de-sus-revistas-escolares-fuente-de-estudio-einterpretacion-historico-educativa.

FIERRO, R. (1950), La pedagogía social de Don Bosco. Buenos Aires: Talleres Gráficos Pedemonte Hnos y Stotland.

HERNÁNDEZ DÍAZ, J. M. (2017), "El boom de la prensa escolar en Canarias en el tardofranquismo y la transición democrática" en Yanes Mesa, J. A., Perera García, E. A., Carrascosa Puertas, L. (coord.), II Congreso Historia del Periodismo Canario: De la autarquía Franquista a la globalización, 1936-2016, pp. 241-256.

HERNÁNDEZ-SAMPIERI, R., FERNANDEZ, C., BAPTISTA, P. (2014), Metodología de la investigación, México D. F.: McGRAW-HILL / Interamericana Editores.

LANGA-NUÑO, C. (2009), "La comunicación durante la guerra civil y el primer franquismo (1936-1950)", en Langa-Nuño, C., Romero-Domínguez, L.R., Ruiz Acosta, M.J. (coord.) Un siglo de información en Sevilla: (prensa, radio y televisión): 1909-2009, pp. 125-164.

LÓPEZ NOGUERO, Fernando (2002), “EI análisis de contenido como método de investigación”, XXI, Revista de Educación, 4, 167-179.

LULL MARTí, E. (1999), “Prensa escolar y educativa católica en vísperas de la II República. La revista Auras del Colegio, de los jesuitas de Valencia (1917-1936)", Anales de Historia Contemporánea, №. 15, pp. 339-348.

MARTíN GONZÁLEZ, A. (1981), Los salesianos de Utrera en España. Una institución al servicio del pueblo, Sevilla: Inspectoría Salesiana de Sevilla. 
MOLL BAGUR, S., y SUREDA GARCIA, B. (2021), "The Generation of Social Capital and the Conformation of Identities in the Schools of the Spanish Postwar Period (19391945): study of the Montesión School Magazine". Social and Education History. https://doi.org/10.17583/hse.7942.

MONTOYA-RODRÍGUEZ, María-Carmen (2022), "Un caso particular en la provincia: las intermitencias en la historia de la prensa utrerana (1850-2021)", en Antonio CHECA, Carmen ESPEJO-CALA, Concha LANGA-NUÑO, (coord.) y María-Carmen MONTOYA-RODRÍGUEZ (ed.), Historia del periodismo local en la provincia de Sevilla. Contra el olvido de la prensa cercana, Granada, Editorial Comares, pp.89104 (en prensa).

PAYNE, S.G. (2005), El franquismo. Primera parte. Madrid: Arlanza ediciones.

YANES MESA, J. A. (2004), "La prensa escolar en España (1868-2004): perspectiva histórica y panorama actual" en Sanz Establés, C., Sotelo González, J, Rubio Moraga, A.L. (coord), Prensa y periodismo especializado II, pp. 189-200.

VILANOU TORRANO, C. y VILAFRANCA MANGUÁN, I. (2020), "La pedagogía católica italiana: entre el positivismo y el neoidealismo. Notas sobre su presencia en españa (1870-1968)", Hist. educ., no 39, pp. 249-311.

WAIDENFELD, M. (2012), “As escolas católicas de prestígio no Rio de Janeiro: as razões da distinção" En De Castro, S. y Waidenfeld, M., A história da educação em debate: estudos comparados, profissão docente, infância, família e Igreja. Mauad X y Faperj. 